\title{
Short Communication: Use of Culling Information in Genetic Evaluation of Fertility and Mastitis in Norwegian Red Cows
}

\author{
M. Holtsmark, ${ }^{* 1}$ B. Heringstad, ${ }^{*} †$ P. Madsen, $\ddagger$ and J. Ødegård ${ }^{*} \S$ \\ *Department of Animal and Aquacultural Sciences, Norwegian University of Life Sciences, PO Box 5003, N-1432 Ås, Norway \\ †Geno Breeding and Al Association, PO Box 5003, N-1432 Ås, Norway \\ łDepartment of Breeding and Genetics, Faculty of Agricultural Sciences, University of Århus, Research Centre Foulum, DK-8830 Tjele, Denmark \\ $\S N o f i m a$, PO Box 5010, N-1432 Ås, Norway
}

\section{ABSTRACT}

Breeding values for clinical mastitis, interval from calving to first insemination, and 56-d nonreturn rate for heifers and primiparous cows, were predicted using multivariate linear-threshold sire models, with or without including information on culling during the first lactation. Breeding values for 3,064 sires were predicted using 3 data sets with an average of 273 , 135, and 68 first-crop daughters per sire, respectively. For each data set, accuracies of selection for health and fertility traits were evaluated through the predictive ability of predicted sire breeding values with respect to phenotypic performance of second-crop daughters. The predictive ability of estimated breeding values for clinical mastitis and interval from calving to first insemination did not improve when including information on early culling, irrespective of the size of first-crop daughter groups. For 56-d nonreturn rates (heifer and primiparous cow), sire evaluations based on reduced size of daughter groups tended to predict performance of the future daughters slightly better when including data on early culling. Hence, for breeding programs with direct selection for health and fertility traits there is little to gain by including early culling as additional information.

Key words: predictive ability, breeding value, culling, fertility, mastitis

Health and fertility problems increase costs of dairy production and increase the risk of early culling. Consequently, health and fertility traits are directly or indirectly included in the breeding goal for dairy cattle in many countries (Interbull, 2008). Because of low heritabilities, relatively large numbers of daughters

Received March 25, 2008.

Accepted June 25, 2008.

${ }^{1}$ Corresponding author: marte.holtsmark@umb.no per sire are required in genetic evaluations of these traits to obtain satisfactory accuracies of selection.

Genetic correlations of early culling or survival with health and fertility traits are moderate to low. Heringstad et al. (2003) and Holtsmark et al. (2008), for example, reported genetic correlations of 0.36 and 0.53 , respectively, for first lactation culling with mastitis, whereas Haile-Mariam et al. (2003) reported a genetic correlation of -0.33 between first lactation survival and calving interval. Information on longevity, which is rather easy to obtain, could therefore be used in genetic evaluation of these traits, through inclusion as a correlated trait in a multiple trait model. The aim of this study was to examine the additional effect of utilizing information about early culling on the predictive ability of the sire EBV for health and fertility traits. The effect was evaluated for large (on average 273 daughters per sire) and smaller progeny group sizes (on average 135 and 68 daughters per sire).

Data was from the Norwegian Dairy Herd Recording system. A data set (data 1a) with information on 836,452 first-crop daughters (i.e., difference between birth year of sire and birth year of daughter was less than 6 yr) of 3,064 Norwegian Red sires was used for prediction of breeding values. This was the same data set as Holtsmark et al. (2008) used to estimate (co)variance components for the traits included in this study. A second data set (data 2) had health and fertility information for 1,413,549 second-crop daughters (i.e., difference between birth year of sire and birth year of daughter was at least $6 \mathrm{yr}$ ) of 409 elite sires (sires included in data 1a, having at least 1,000 second-crop daughters). This data set was used to evaluate the predictive ability of sire EBV. The data sets included cows with first calving from 1980 through 2004, and age at first calving (for those daughters that had a recorded calving) from 20 through 40 mo. Data 1a was further restricted to cows from herd 5-yr periods with at least 5 primiparous cows.

Seven traits were included: 1) culling from the herd in first lactation (CULL), scored as 0 for cows which 
Table 1. Number of cows with records of the different traits in data set 1a; 305-d protein yield (PY305), interval from calving to first insemination (CFI), lactation mean SCS (LSCS), culling in first lactation (CULL), clinical mastitis (CM), and 56-d nonreturn for heifers (NR0), and primiparous cows (NR1)

\begin{tabular}{lccccccc}
\hline Trait & PY305 & CFI & LSCS & CULL & CM & NR0 & NR1 \\
\hline Records, $n$ & 638,893 & 524,268 & 638,607 & 733,487 & 735,548 & 659,904 & 526,454 \\
\hline
\end{tabular}

had a second calving or were culled later than $365 \mathrm{~d}$ after first calving, and 1 otherwise; 2) clinical mastitis (CM) in the interval from $30 \mathrm{~d}$ before to $300 \mathrm{~d}$ after first calving, scored as 1 if the cow was treated at least once, and 0 otherwise; 3) lactation mean somatic cell score (LSCS); 4) 305-d protein yield (PY305); 5 and 6) nonreturn rate within $56 \mathrm{~d}$ for heifers (NR0) and primiparous cows (NR1), scored as returned (0) if the cow had a second insemination from 6 to $56 \mathrm{~d}$ after the first insemination and nonreturn (1) otherwise (a new insemination 0 to $5 \mathrm{~d}$ after a first one was considered to be a double insemination); and 7) interval from calving to first insemination (CFI), required to be in the interval 20 and $210 \mathrm{~d}$. To examine the effect of reduced size of daughter groups 2 additional data sets were created based on data 1a, by keeping records from every second (data 1b), or every fourth (data 1c) herd. All sires were represented in all data sets. The number of records per trait for data $1 \mathrm{a}$ is in Table 1 . Because every second and every fourth herd were sampled at random when generating data $1 \mathrm{~b}$ and $1 \mathrm{c}$, the number of records for each trait in these data sets will be about 50 and $25 \%$, respectively, of the number of records in data 1a (Table 1). Number of cows per data set, number of daughters per sire, and number of CULL records per data set are in Table 2. The sire pedigree file had information on sires and maternal grandsires of the 3,064 sires with daughters in the data set, traced back as far as possible, and included a total of 3,756 males.

For data sets 1a, 1b, and 1c, sire EBV were predicted using a 7-trait model (including CULL) or a 6-trait model (without CULL). The 7-trait model was the multi-trait linear-threshold sire model used in Holtsmark et al. (2008):

$$
\mathbf{Y}=\mathbf{X} \boldsymbol{\beta}+\mathbf{Z}_{1} \mathbf{h}+\mathbf{Z}_{2} \mathbf{s}+\mathbf{e}
$$

where $\mathbf{Y}$ is a vector of liabilities for the binary traits and phenotypic observations for the continuous traits; $\boldsymbol{\beta}=\left[\boldsymbol{\beta}_{\mathrm{NR} 0}{ }^{\mathrm{t}} \boldsymbol{\beta}_{\mathrm{NR} 1}{ }^{\mathrm{t}} \boldsymbol{\beta}_{\mathrm{CFI}}{ }^{\mathrm{t}} \boldsymbol{\beta}_{\mathrm{CM}}{ }^{\mathrm{t}} \boldsymbol{\beta}_{\mathrm{LSCS}}{ }^{\mathrm{t}} \boldsymbol{\beta}_{\mathrm{PY} 305}{ }^{\mathrm{t}} \boldsymbol{\beta}_{\mathrm{CULL}}\right]^{\mathrm{t}}$ is a vector of trait specific "fixed" effects, where $\boldsymbol{\beta}_{\mathrm{NR} 0}$ includes effects of double insemination ( 2 classes), age at first insemination (21 classes), and month-year of first insemination (316/316/315 classes for data $1 \mathrm{a} / 1 \mathrm{~b} / 1 \mathrm{c})$ for heifers, $\boldsymbol{\beta}_{\mathrm{NR} 1}$ contains effects of double insemination, age at first calving (20 classes), and month-year of first insemination after first calving (297/296/296 classes for data sets 1a/1b/1c) for cows, whereas $\boldsymbol{\beta}_{\mathrm{CFI}}, \boldsymbol{\beta}_{\mathrm{CM}}, \boldsymbol{\beta}_{\mathrm{LSCS}}$, $\boldsymbol{\beta}_{\mathrm{PY} 305}$, and $\boldsymbol{\beta}_{\mathrm{CULL}}$ includes effects of age at first calving (21 classes, except 20 for CFI) and month-year of first calving (288 classes); $\mathbf{h}$ is a vector of random herd-5year effects $\mathbf{h}=\left[\mathbf{h}_{\mathrm{NR} 0}{ }^{\mathrm{t}} \mathbf{h}_{\mathrm{NR} 1}{ }^{\mathrm{t}} \mathbf{h}_{\mathrm{CFI}}{ }^{\mathrm{t}} \mathbf{h}_{\mathrm{CM}}{ }^{\mathrm{t}} \mathbf{h}_{\mathrm{LSCS}}{ }^{\mathrm{t}} \mathbf{h}_{\mathrm{PY} 305}{ }^{\mathrm{t}}\right.$ $\left.\mathbf{h}_{\mathrm{CULL}}{ }^{\mathrm{t}}\right]^{\mathrm{t}}$, where $\mathbf{h}_{\mathrm{NR} 0}$ contains the random effects of the herd-5-yr period of first insemination as heifer, whereas $\mathbf{h}_{\mathrm{NR} 1}, \mathbf{h}_{\mathrm{CFI}}, \mathbf{h}_{\mathrm{CM}}, \mathbf{h}_{\mathrm{LSCS}}, \mathbf{h}_{\mathrm{PY} 305}$, and $\mathbf{h}_{\mathrm{CULL}}$ contain the random herd-5-yr effects of first calving; $\mathbf{s}=\left[\mathbf{s}_{\mathrm{NR} 0}{ }^{\mathrm{t}} \mathbf{s}_{\mathrm{NR} 1}{ }^{\mathrm{t}}\right.$ $\left.\mathbf{s}_{\mathrm{CFI}}{ }^{\mathrm{t}} \mathbf{s}_{\mathrm{CM}}{ }^{\mathrm{t}} \mathbf{S}_{\mathrm{LSCS}}{ }^{\mathrm{t}} \mathbf{S}_{\mathrm{PY} 305}{ }^{\mathrm{t}} \mathbf{s}_{\mathrm{CULL}}\right]^{\mathrm{t}}$ is a vector of sire effects; $\mathbf{e}$ is a vector of random residuals; and $\mathbf{X}, \mathbf{Z}_{1}$, and $\mathbf{Z}_{2}$ are the corresponding incidence matrices. Independent bounded uniform priors were assumed for the fixed effects. Residuals were assumed to be independent across cows, but correlated across traits within cow, following a multivariate normal distribution, $\mathbf{e} \sim \mathrm{N}(0, \mathbf{R I})$, where $\mathbf{R}$ is a $7 \times 7$ (co)variance matrix containing the posterior means of the corresponding residual (co)variance components obtained in Holtsmark et al. (2008). Likewise, multivariate normal prior distributions were assigned for sire and herd-5-yr effects: $\mathbf{s} \mid \mathbf{A}, \mathbf{G} \sim \mathrm{N}(0, \mathbf{G} \otimes \mathbf{A})$, and $\mathbf{h} \mid \mathbf{H} \sim \mathrm{N}(0, \mathbf{H} \otimes \mathbf{I})$, respectively, where $\mathbf{G}$ and $\mathbf{H}$ are $7 \times$ 7 (co)variance matrices containing posterior means of the corresponding sire and herd-5-yr (co)variances from Holtsmark et al. (2008), A is the additive genetic relationship matrix of the 3,756 sires, and $\mathbf{I}$ is an identity

Table 2. Total number of cows, average, and minimum/maximum number of daughters per sire, number of animals with culling recorded (all lactations), and percentage of the latter being culled in the first lactation in data sets 1a, 1b, and 1c, containing all, every second, and every fourth herd, respectively

\begin{tabular}{lcccc}
\hline Data s $^{1}$ & Cows, $\mathrm{n}$ & $\begin{array}{c}\text { Average number } \\
\text { of daughters }\end{array}$ & $\begin{array}{c}\text { Minimum/maximum } \\
\text { number }\end{array}$ & $\begin{array}{c}\text { Recorded } \\
\text { culled, } \mathrm{n}\end{array}$ \\
\hline 1a & 836,452 & 272.99 & $27 / 488$ & 733,487 \\
1b & 414,655 & 135.33 & $11 / 231$ & 363,882 \\
1c & 201,461 & 67.65 & $8 / 122$ & 181,552 \\
\hline
\end{tabular}

${ }^{1}$ Data set $1 \mathrm{a}, 1 \mathrm{~b}$, and $1 \mathrm{c}$ had on average 273,135 , and 68 daughters per sire, respectively. 
Table 3. Pearson correlation between predicted breeding values of sires and average performance of their 2 crop daughters for clinical mastitis (CM), 56-d nonreturn as heifers (NR0) and primiparous cows (NR1), and interval from calving to first insemination (CFI), with information on culling in the first lactation included (Incl.) or excluded (Excl.) from the analysis

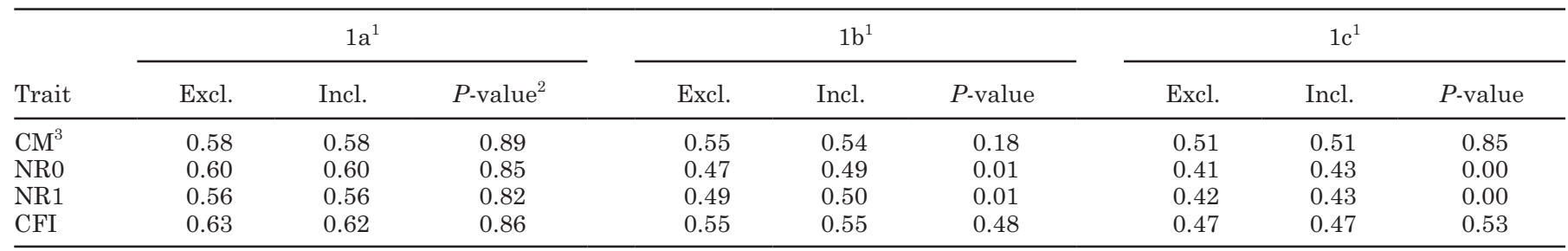

${ }^{1}$ Data set $1 \mathrm{a}, 1 \mathrm{~b}$, and $1 \mathrm{c}$ had on average 273,135 , and 68 daughters per sire, respectively.

${ }^{2}$ Probability of difference between correlations obtained within trait and data set.

${ }^{3}$ Only 395 of the 409 elite sires had $\geq 1,000$ daughters with CM records. For the remaining traits all 409 sires had $\geq 1,000$ daughters with records.

matrix with rank equal to number of herd-5-yr effects $(69,798 / 34,723 / 17,363$ periods for data $1 \mathrm{a} / 1 \mathrm{~b} / 1 \mathrm{c})$.

The 6-trait model was identical to the model above, except that the trait CULL was excluded from the analysis.

The data were analyzed using Markov chain Monte Carlo methods with the Gibbs-sampling routine of the DMU software (Madsen and Jensen, 2006), using the input (co)variance matrices estimated in Holtsmark et al. (2008) as true parameters. Assuming all (co)variance components were known, only the location parameters were sampled. To assess whether the Gibbs sampling had converged, 2 independent chains of 1,500 and 3,000 samples were generated for each data set, and the correlation between the posterior means of the predicted breeding values of sires were examined. As all correlations were $>0.99$, all chains were considered to have converged and the posterior means obtained from the longest chains with 3,000 samples (after a burn-in of 1,000) were used.

The additional value of including information on CULL in the prediction of breeding values for CM, CFI, NR0, and NR1 was evaluated for data sets $1 \mathrm{a}, 1 \mathrm{~b}$, and $1 \mathrm{c}$ based on the Pearson correlation coefficient between the predicted breeding values and the average phenotypic performance of second-crop daughters. Equality of Pearson correlation coefficients was tested using a pair-wise $t$-test (Williams's modification of Hotelling's test; Dunn and Clark, 1971). For the binary traits (CM, NR0, and NR1), the predictive ability was also examined based on the Pearson chi-square statistics $\left(x^{2}\right)$ based on logistic regression of the average performance of the second-crop daughters on predicted sire evaluations from first-crop daughters. The Pearson chi-square statistics for model $m$ can be written as

$$
\chi_{m}^{2}=\sum_{s=1}^{q}\left[n_{s}\left(\frac{\left(r_{s}-\hat{p}_{m s}\right)^{2}}{\hat{p}_{m s}}+\frac{\left(\hat{p}_{m s}-r_{s}\right)^{2}}{\left(1-\hat{p}_{m s}\right)}\right)\right],
$$

where $q$ is the number of elite sires, $n_{s}$ is the number of second-crop daughters for sire $s, r_{s}$ is the success rate (e.g., mastitis frequency) of the second-crop daughters of sire $s$, and $\hat{p}_{m s}$ is the expected success rate of secondcrop daughters of sire $s$, based on logistic regression on predicted sire breeding values from model $\mathrm{m}$. The model that obtained the lowest $\mathrm{x}^{2}$ was considered as

Table 4. Pearson goodness of fit statistics $\left(\mathrm{X}^{2}\right)$ from logistic regression of sire daughter groups on the corresponding sire EBV for clinical mastitis (CM), 56-d nonreturn as heifers (NR0) and primiparous cows (NR1), with information on culling in first lactation included (Incl.) or excluded (Excl.) from the analysis ${ }^{1}$

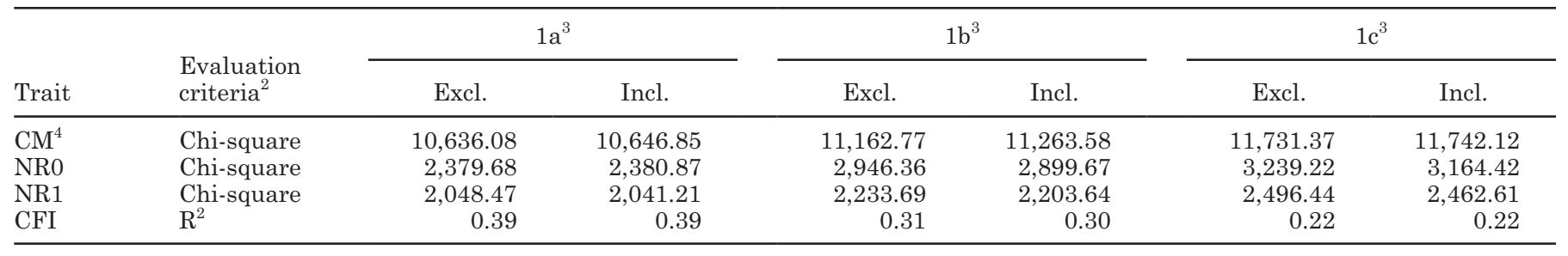

${ }^{1}$ For the interval from calving to first insemination (CFI) coefficient of determination $\left(\mathrm{R}^{2}\right)$ from regression of sire EBV on average performance of second-crop sire daughter groups are presented.

${ }^{2}$ The model obtaining the lowest $\mathrm{X}^{2}$ was considered to be the most accurate.

${ }^{3}$ Data set 1a, 1b, and 1c contained on average 273, 135, and 68 daughters per sire, respectively.

${ }^{4}$ Only 395 of the 409 elite sires had $\geq 1,000$ daughters with CM records. 
the most accurate predictor of performance of future daughters. For CFI the goodness of fit of the predictive ability was assessed by the coefficient of determination $\left(\mathrm{R}^{2}\right)$ obtained from the linear regression of the sire EBV on the average performance of the second-crop daughter groups.

Including information about culling in first lactation (CULL) in addition to the other traits did not improve the predictive ability of the EBV for any of the traits in the full data set (1a) (Tables 3 and 4). With reduced first-crop daughter groups (data $1 \mathrm{~b}$ and $1 \mathrm{c}$ ), the predictive ability of the EBV for NR0 and NR1 tended to improve slightly (2.3 to $5.6 \%$ for the Pearson correlation) when including CULL in the analysis (Tables 3 and 4 ), whereas the predictive ability of the EBV for CM and CFI were not affected by additionally including CULL in any of the data sets analyzed. As expected, reducing the average number of daughters per sire in EBV calculation generally reduced the predictive ability of the EBV (Table 3), as a result of reduced accuracy of selection. The limited effect of including CULL in addition to the other traits may be because CULL rarely contributes new information not already captured by direct recording. For example, if a specific cow is culled due to occurrence of clinical mastitis, the culling record will not provide any additional information on mastitis, but rather a double-counting of the already included mastitis record. This is likely to apply to all traits that can be regarded as underlying causes of culling. If direct information on these traits is not available, early culling could be regarded as a valuable source of information in indirect selection for improved functional traits.

\section{ACKNOWLEDGMENTS}

Access to the data was granted by the Norwegian Dairy Herd Recording System in agreement number 005.2006. This work is part of the project "Selection for reduced risk of early culling in dairy cattle: Comparison of alternative approaches to improve animal welfare" (no. 173276/110) financed by the Research Council of Norway.

\section{REFERENCES}

Dunn, O. J., and V. Clark. 1971. Comparison of tests of the equality of dependent correlation coefficients. J. Am. Stat. Assoc. 66:904908.

Haile-Mariam, M., P. J. Bowman, and M. E. Goddard. 2003. Genetic and environmental relationship among calving interval, survival, persistency of milk yield and somatic cell count in dairy cattle. Livest. Prod. Sci. 80:189-200.

Heringstad, B., R. Rekaya, D. Gianola, G. Klemetsdal, and K. A Weigel. 2003. Bivariate analysis of liability to clinical mastitis and to culling in first lactation cows. J. Dairy Sci. 86:653-660.

Holtsmark, M., B. Heringstad, P. Madsen, and J. Ødegård. 2008. Genetic relationship between culling, milk production, fertility and health traits in Norwegian Red cows. J. Dairy Sci. 91:40064012.

Interbull. 2008. Description of national genetic evaluation systems for dairy cattle traits as applied in different Interbull member countries. http://www-interbull.slu.se/national ges_info2/ framesida-ges.htm Accessed Aug. 4, 2008.

Madsen, P., and J. Jensen. 2006. A User's Guide to DMU. A package for analyzing multivariate mixed models. Version 6, release 4.6. Danish Institute of Agricultural Sciences (DIAS). Dept. of Animal Breeding and Genetics. Research Centre Foulum, Tjele, Denmark. 